\title{
Contribution of methylglyoxal to delayed healing of bone injury in diabetes
}

\author{
TAKAO AIKAWA $^{1}$, HIDENORI MATSUBARA ${ }^{1}$, SHUHEI UGAJI ${ }^{1}$, JUNICHI SHIRAKAWA ${ }^{2}$, RYOJI NAGAI ${ }^{2}$, \\ SEIICHI MUNESUE ${ }^{3}$, AI HARASHIMA ${ }^{3}$, YASUHIKO YAMAMOTO ${ }^{3}$ and HIROYUKI TSUCHIYA ${ }^{1}$ \\ ${ }^{1}$ Department of Orthopaedic Surgery, Kanazawa University Graduate School of Medical Sciences, \\ Kanazawa 920-8641; ${ }^{2}$ Laboratory of Food and Regulation Biology, Graduate School of Agriculture, \\ Tokai University, Minamiaso, Aso-gun, Kumamoto 869-1404; ${ }^{3}$ Department of Biochemistry and \\ Molecular Vascular Biology, Kanazawa University Graduate School of Medical Sciences, Kanazawa 920-8640, Japan
}

Received December 31, 2016; Accepted March 6, 2017

DOI: $10.3892 / \mathrm{mmr} .2017 .6589$

\begin{abstract}
Patients with diabetes are vulnerable to delayed bone fracture healing or pseudoarthrosis. Chronic sustained hyperglycemia, reactive intermediate derivatives of glucose metabolism, such as methylglyoxal (MGO), and advanced glycation end-products (AGEs) are implicated in diabetic complications. In the present study, it was examined whether MGO is able to cause disturbed bone healing in diabetes. Diabetes was induced in male mice by injection of streptozotocin $(50 \mathrm{mg} / \mathrm{kg})$ for 5 days. A bone defect $(1.0-\mathrm{mm}$ diameter) was created in the left distal femur, and bone repair was assessed from an examination of computed tomography scans. ST2 cells were exposed to MGO (0-400 $\mu \mathrm{M})$ to investigate osteoblastic differentiation, cell viability, and damage. Consequently, blood glucose and hemoglobin A1c levels in diabetic mice were determined to be $493 \pm 14.1 \mathrm{mg} / \mathrm{dl}$ and $8.0 \pm 0.05 \%$, respectively. Compared with non-diabetic control mice, diabetic mice exhibited markedly delayed bone healing, with increased levels of the MGO-derived AGEs, $N^{\varepsilon}$-(carboxymethyl)-lysine and $N^{\delta}$-(5-hydro-5-methyl-4-imida zolone-2-yl)-ornithine, in the sera and femurs. MGO inhibited the osteoblastic differentiation of ST2 cells in a dose-dependent manner, and markedly decreased cell proliferation through cytotoxicity. In conclusion, MGO has been demonstrated to cause impaired osteoblastic differentiation and delayed bone repair in diabetes. Therefore, detoxification of MGO may be
\end{abstract}

Correspondence to: Dr Takao Aikawa, Department of Orthopaedic Surgery, Kanazawa University Graduate School of Medical Sciences, 13-1 Takara-machi, Kanazawa 920-8641, Japan E-mail: tak-aikawa@med.kanazawa-u.ac.jp

Professor Yasuhiko Yamamoto, Department of Biochemistry and Molecular Vascular Biology, Kanazawa University Graduate School of Medical Sciences, 13-1 Takara-machi, Kanazawa 920-8640, Japan

E-mail: yasuyama@med.kanazawa-u.ac.jp

Key words: methylglyoxal, glycation, bone injury repair, diabetes a potentially useful strategy against bone problems in patients with diabetes.

\section{Introduction}

Osteoporosis is a bone condition characterized by low bone mass, increased fragility, decreased bone quality, and an increased fracture risk (1). It often becomes symptomatic when a fracture occurs accidentally. The incidence of fractures is known to increase with age, consequently leading to a high mortality rate and an overall functional decline in elder patients with osteoporosis. It has been reported that the mortality rate during the first year following a hip fracture is 36 and $21 \%$ for men and women, respectively (2). As with aging, poor glycemic control in diabetes is a well-known risk factor for bone fracture. For example, patients with type 1 diabetes are reported to have a 6.9-fold higher risk for hip fracture, with decreased bone mineral density (BMD) (1). There is also increasing evidence supporting an association between type 2 diabetes and increased fracture risk (2-4). The Rotterdam study revealed that individuals with type 2 diabetes had a $69 \%$ increased fracture risk compared with those without diabetes, despite having higher BMD (5). In addition, impaired fracture healing is also demonstrated in diabetes $(2-4,6,7)$. Bone fracture healing in diabetes was reported to be prolonged by $87 \%$ with a 3.4 -fold higher risk of delayed union, non-union, redislocation, or pseudoarthrosis $(3,8,9)$, which are commonly observed in type 1 and type 2 diabetes. These bone problems, such as osteoporosis and delayed fracture healing, are thus recognized as additional complications of longstanding diabetes.

Several mechanisms, including insulin insufficiency, hyperglycemia, and oxidative stress, are considered to delay fracture healing in type 1 and type 2 diabetes via the reduction of osteoblast differentiation, increased osteoclast activity, and induction of apoptosis in chondrocytes and osteoblasts (7,10-12). Of these, chronic and sustained hyperglycemia is known to enhance the glycation reaction, and ultimately results in the formation of advanced glycation end-products (AGEs). The accumulation of AGEs has been associated with diabetic complications, as well as various aging-associated 
diseases, including Alzheimer's disease and osteoporosis. Notably, AGEs are reported to inhibit osteoblastic differentiation and to induce apoptosis in osteoblasts, leading to decreased osteoblast numbers and impaired bone formation $(13,14)$. Methylglyoxal (MGO) is a cell-permeant molecule, highly deleterious and the most potent glycating agent for very rapid generation of AGEs in cellular macromolecules $(15,16)$. In the glycation reaction, $\mathrm{MGO}$ is up to 20,000-fold more reactive compared with glucose. The most important endogenous source of MGO is the fragmentation of the triose phosphates, glyceraldehyde 3-phosphate and dihydroxyacetone phosphate, via the glycolytic pathway $(17,18)$. MGO may also be produced as a by-product of protein and fatty acid metabolism (19-21). MGO formation is known to be increased in patients with diabetes (22). Therefore, MGO may be implicated in affecting bone-healing processes in diabetes; however, direct evidence has not been provided using an in vivo bone-healing model.

In the present study, the effect of MGO on the differentiation, growth and cytotoxicity of osteoblastic cells in vitro was examined, and the accumulation of MGO-derived AGEs in the sera and femurs was measured using an in vivo bone defect mouse model with or without streptozotocin (STZ)-induced diabetes.

\section{Materials and methods}

Cell culture. Mouse ST2 cells (Riken Cell Bank, Tsukuba, Japan) were cultured in $\alpha$-minimum essential medium (5.5 mmol/l glucose; Wako Pure Chemical Industries, Osaka, Japan), supplemented with $10 \%$ fetal bovine serum, $100 \mathrm{U} / \mathrm{ml}$ penicillin, and $100 \mu \mathrm{g} / \mathrm{ml}$ streptomycin in $5 \% \mathrm{CO}_{2}$ at $37^{\circ} \mathrm{C}$. To induce osteoblastic differentiation in the ST2 cells, $10 \mathrm{mM}$ $\beta$-glycerophosphate, $0.1 \mu \mathrm{M}$ dexamethasone, and $50 \mu \mathrm{M}$ ascorbic acid were added to the cell culture medium. For the assays, 0, 50, 200, or $400 \mu \mathrm{M}$ MGO (Sigma-Aldrich; Merck KGaA, Darmstadt, Germany) was added to the differentiation medium, and the medium was changed every other day.

Alkaline phosphatase (ALP) activity assay. ALP activity in the ST2 cells was determined 7 days after the induction of osteoblastic differentiation, using a TRACP \& ALP Assay kit (Takara Bio, Inc., Otsu, Japan), according to the manufacturer's protocol.

Mineralization assay. Calcium deposition was evaluated 28 days after differentiation of the ST2 cells. An In Vitro Osteogenesis Assay kit (EMD Millipore, Billerica, MA, USA) was used for alizarin red staining and quantitative analysis, following the manufacturer's protocols.

Cell proliferation assay. ST2 cell proliferation was assayed by the cell-based WST-1 method using a Cell Proliferation Assay kit (Chemicon ${ }^{\circledR}$; EMD Millipore), at 7 and 14 days after the induction of differentiation, according to the manufacturer's protocol.

Cytotoxicity assay. ST2 cells were seeded on 6-well plates at a density of $10^{5}$ cells/well. After $48 \mathrm{~h}$, osteoblastic differentiation was induced by the addition of $0,50,200$, or $400 \mu \mathrm{M}$ MGO. After $72 \mathrm{~h}$, release of the enzyme, lactate dehydrogenase
(LDH), was assayed using a Non-Radioactive Cytotoxicity assay (Promega Corp., Madison, WI, USA), according to the manufacturer's protocol.

Experimental animals and induction of diabetes. Male C57BL/6J mice (weight, $21 \mathrm{~g}$ ) at 6 weeks of age were purchased from Charles River Japan, Inc. (Yokohama, Japan), and acclimatized for 1 week prior to the start of the experiment. To induce diabetes, the mice $(n=37)$ were intraperitoneally injected with STZ (50 mg/kg body weight) daily for 5 days, according to the Animal Models of Diabetic Complications Consortium (AMDCC) protocols. By contrast, sodium citrate buffer was injected into control mice $(n=28)$. After 3 weeks, non-fasting blood glucose levels were measured using a glucometer (Glutest Ace, Sanwa Kagaku, Japan), using whole blood obtained from the tail vein. Mice with blood glucose levels $>300 \mathrm{mg} / \mathrm{dl}$ were considered to be diabetic. Hemoglobin A1c (HbA1c) was measured in tail vein blood using a DCA Vantage analyzer (Siemens Healthineers, Erlangen, Germany). Mice were maintained under standard cage conditions $\left(24^{\circ} \mathrm{C}\right.$; 12-h light/dark cycle, lights on at 8:45 a.m.) with sawdust bedding, and access to food and water ad libitum. All animal experiments were approved by the Committee on Animal Experimentation of Kanazawa University, and performed in accordance with the Fundamental Guidelines for Proper Conduct of Animal Experiment and Related Activities in Academic Research Institutions under the jurisdiction of the Ministry of Education, Culture, Sports, Science, and Technology of Japan.

Induction of drill-hole injury in the femur. Under anesthesia with a mixture of medetomidine $(0.3 \mathrm{mg} / \mathrm{kg})$, midazolam (4.0 mg/kg) and butorphanol $(5.0 \mathrm{mg} / \mathrm{kg})$, a straight, longitudinal skin incision $(5 \mathrm{~mm})$ was made in the distal femur of the mice, and the periosteal membrane was subsequently stripped away, following muscle splitting, to expose the bone surface. A drill-hole injury was then introduced by inserting a drill bit with a diameter of $0.9 \mathrm{~mm}$ fixed to a finger handle at the medial portion of the diaphysis of the left femur, $5 \mathrm{~mm}$ above the knee joint. The hole was drilled through the collateral cortical bone and bone marrow, and thus a round defect measuring $\sim 1.0 \mathrm{~mm}$ in diameter was made. The hole was irrigated with saline solution to prevent thermal necrosis of the margins. The incised skin was subsequently sutured in a sterile manner, and anesthesia was discontinued. During the surgery, the body temperature was maintained at $37^{\circ} \mathrm{C}$ using a heating pad.

Computed tomography (CT) scanning. Mice were anesthetized using the aforementioned procedure, and femurs were scanned using an X-ray CT system (Latheta LCT-200; Hitachi Aloka Medical, Tokyo, Japan) at 3, 7, 10, and 14 days after bone injury. The healing process in the bone defect area was evaluated using suitable analysis software (AzeWin; AZE, Ltd., Tokyo, Japan). Images were processed in a multiplanar reconstruction, according to oblique coronal planes, maintaining working axes parallel to the center line of the bone defect. CT values at the area of bone defect were calculated at each phase.

Measurement of MGO-derived AGEs. Collected serum was stored at $-80^{\circ} \mathrm{C}$ prior to analysis. Serum levels of 
the MGO-derived AGEs, $N^{\varepsilon}$-(carboxymethyl)-lysine (CML) and $N^{\delta}$-(5-hydro-5-methyl-4-imidazolone2-yl)-ornithine (MG-H1), were measured using liquid chromatography-tandem mass spectrometry (LC-MS/MS), as previously described (23). Briefly, low-molecular-weight fractions $(<3,000 \mathrm{kDa})$ in the serum $(50 \mu \mathrm{l})$ were separated using a Vivaspin ${ }^{\circledR}$ centrifugal concentrator (Vivaspin ${ }^{\circledR}$ 500; Sartorius Stedim Biotech, Goettingen, Germany) according to the manufacturer's protocol, and then reduced with sodium borohydride $\left(\mathrm{NaBH}_{4}\right)$ (Sigma-Aldrich; Merck KGaA). Standard $\left[{ }^{2} \mathrm{H}_{2}\right] \mathrm{CML}(0.01 \mathrm{nmol})$ and $\left[{ }^{2} \mathrm{H}_{2}\right] \mathrm{MG}-\mathrm{H} 1$ (0.01 nmol) (PolyPeptide Laboratories, Strasbourg, France), and $\left[{ }^{13} \mathrm{C}_{6}\right]$ lysine $(5 \mathrm{nmol})$ (Cambridge Isotope Laboratories, Inc., Tewksbury, MA, USA), were added to the reduced samples. The prepared samples were subsequently passed through a Strata-X-C column (Phenomenex, Torrance, CA, USA) and assayed by LC-MS/MS using a TSQ Vantage triple-stage quadrupole mass spectrometer (Thermo Fisher Scientific, Waltham, MA, USA). AGE structures, lysine, and the standards were detected using electrospray positive ionization-mass spectrometric multiple reaction monitoring.

The femur samples were cleaned of periosteal membrane and bone marrow, and subsequently frozen and pulverized in liquid nitrogen, as previously described (24). The levels of CML and MG-H1 in the specimens were also quantified by LC-MS/MS serum sample measurement (24). Briefly, bone powder was demineralized with $0.5 \mathrm{M}$ EDTA in $50 \mathrm{mM}$ Tris buffer ( $\mathrm{pH}$ 7.4) for $96 \mathrm{~h}$ at $4^{\circ} \mathrm{C}$. Demineralized bone residues were reduced at room temperature with $\mathrm{NaBH}_{4}$. Specimens were hydrolyzed in $6 \mathrm{M} \mathrm{HCl}$ at $100^{\circ} \mathrm{C}$ for $18 \mathrm{~h}$. The prepared samples were then assayed using $\left[{ }^{2} \mathrm{H}_{3}\right]$ hydroxyproline $(\mathrm{C} / \mathrm{D} / \mathrm{N}$ Isotopes Inc., Quebec, Canada).

Statistical analysis. Data are expressed as the mean \pm standard error of the mean. P-values were calculated using a two-tailed Student's t-test for pairwise comparisons, and one-way analysis of variance followed by Bonferroni's test for multiple comparisons (Ekuseru-Toukei 2012 software; SSRI, Tokyo, Japan), unless otherwise stated. $\mathrm{P}<0.05$ was considered to indicate a statistically significant difference.

\section{Results}

Bone defect repair in STZ-induced diabetic mice. Compared with non-diabetic control mice, the diabetic mice exhibited marked decreases in body weight $(27 \pm 0.3$ vs. $23 \pm 0.3 \mathrm{~g})$ and significantly increased levels of non-fasting blood glucose $(140 \pm 3.8$ vs. $493 \pm 14.1 \mathrm{mg} / \mathrm{dl})$ and HbA1c $(4.0 \pm 0.05 \%$ vs. $8.0 \pm 0.16 \%$; control vs. diabetic mice, respectively) at 3 weeks after the STZ injection $(\mathrm{P}<0.05$; Table I). After confirming the presence of overt diabetic conditions in the mice, a drill-hole injury (1.0 $\mathrm{mm}$ in diameter) was introduced at the medial portion of the diaphysis of the left femur $(5 \mathrm{~mm}$ above the knee joint) to check the recovery rate from bone injury. The healing process in the bone defect area was subsequently evaluated using CT scanning at days 3, 7, 10 and 14 after injury (Fig. 1A). CT imaging of the bone defect lesions revealed no significant differences in ossification between the non-diabetic and the diabetes-induced mice at the early healing stage on day 3 (Fig. 1A and B). However, repair of the
Table I. Diabetic status of STZ-induced mice.

\begin{tabular}{lcc}
\hline Measurement & $\begin{array}{c}\text { Control } \\
(\mathrm{n}=28)\end{array}$ & $\begin{array}{c}\text { STZ-induced } \\
(\mathrm{n}=37)\end{array}$ \\
\hline Body weight $(\mathrm{g})$ & $27 \pm 0.3$ & $23 \pm 0.3^{\mathrm{a}}$ \\
Blood glucose (mg/dl) & $140 \pm 3.8$ & $493 \pm 14.1^{\mathrm{a}}$ \\
HbA1c (NGSP, \%) & $4.0 \pm 0.05$ & $8.0 \pm 0.16^{\mathrm{a}}$ \\
\hline
\end{tabular}

${ }^{\mathrm{a}} \mathrm{P}<0.05$; the data are expressed as mean \pm standard error of the mean. NGSP, National Glycohemoglobin Standardization Program; STZ, streptozotocin.

damaged site on the femur was significantly delayed at days 7 and 10 in diabetic mice, corresponding to intramembranous bone formation, chondrogenesis and early endochondral bone phases. In non-diabetic controls, recovery peaked at day 10 , and reached a plateau thereafter (Fig. 1A and B).

Diabetes alteredbone quality throughincreasedaccumulations of $C M L$ and $M G-H 1$. Subsequently, the accumulation of MGO-derived AGEs, CML, and MG-H1 in sera and femurs under diabetic conditions was investigated. In the sera from diabetic mice, the levels of CML and MG-H1, as quantified by LC-MS/MS, were significantly increased compared with those in non-diabetic controls (Fig. 2A). Similarly, higher levels of femur CML and MG-H1 were observed in diabetic mice compared with control mice (Fig. 2B). These findings suggested that MGO generated under diabetic conditions is able to affect bone defect healing in our animal model.

Effect of MGO on in vitro osteoblastic differentiation of ST2 cells. Impairment of osteoblastic differentiation is an important factor in the pathogenesis of detrimental bone repair. To address the effect of MGO on osteoblastic differentiation, the mouse stromal ST2 cell line was used, which is an established cell culture model characterized by its potency to differentiate into cells with the typical characteristics of osteoblasts, and the formation of mineralized nodules $(25,26)$. Using ALP activity as an osteoblastic differentiation marker, ST2 cells were cultured in induction media with MGO at a final concentration of $0,50,200$, or $400 \mu \mathrm{M}$. MGO exposure for 7 days decreased ALP activity in a dose-dependent manner, and significantly inhibited osteoblastic differentiation of ST2 cells at 200 and $400 \mu \mathrm{M}$ MGO $(\mathrm{P}<0.05$ and $\mathrm{P}<0.01$, respectively; Fig. 3A and B). Matrix mineralization, the final step of osteoblast differentiation, serves a critical role in maintaining the mechanical integrity of bone tissues.

Subsequently, the effects of MGO on mineralization were examined using alizarin red staining after 28 days of differentiation. In the presence of MGO, dose-dependent decreases in calcium deposition in ST2 cells were observed, which were statistically significant at 200 and $400 \mu \mathrm{M}$ MGO $(\mathrm{P}<0.05$ and $\mathrm{P}<0.01$, respectively; Fig. $3 \mathrm{C}$ and D). These results indicated that exposure to MGO led to disrupted osteoblastic differentiation.

Effect of MGO on cell viability and cytotoxicity in ST2 cells. Subsequently, it was examined whether MGO may affect 
A


3

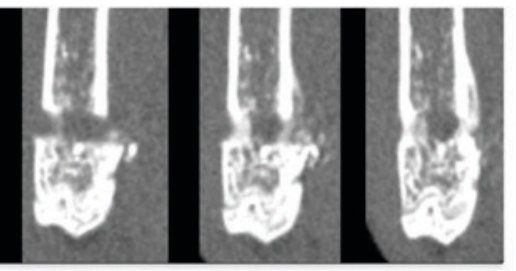

7

10

14 days

B

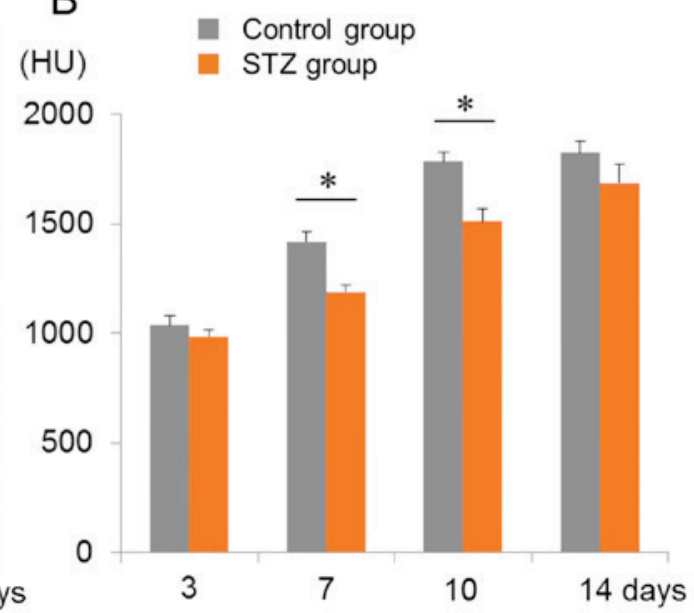

Figure 1. Evaluation of bone defect repair by CT scanning. (A) The recovery of bone injury lesions (drill-hole, $1.0 \mathrm{~mm}$ in diameter) in the left femur was followed and evaluated using CT scanning at days 3, 7, 10, and 14 after the bone injury. (B) Quantitative evaluation of the CT imaging of bone defect lesions. Cont group, non-diabetic control mice $(n=6)$; STZ group, streptozotocin-induced diabetic mice $(n=6)$. " $\mathrm{P}<0.05$ vs. the control. Values are presented as the mean \pm standard error of the mean. STZ, streptozotocin; HU, hounsfield unit.
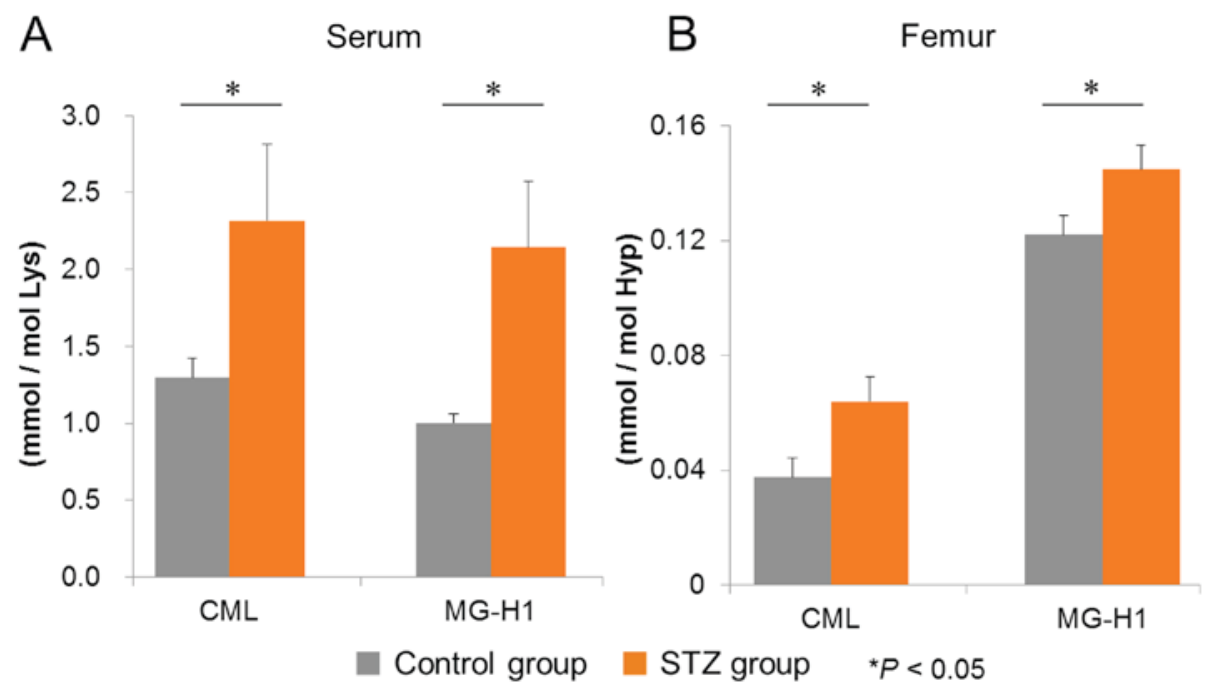

Figure 2. Quantitative evaluation of AGEs in sera and femurs by LC-MS/MS. (A) Serum and (B) femur levels of the MGO-derived AGEs, CML and MG-H1, were measured by LC-MS/MS, as described in the Materials and methods section. The control and the STZ diabetes-induced groups both contained $\mathrm{n}=6 \mathrm{mice}$. Values are presented as the mean \pm standard error of the mean. ${ }^{*} \mathrm{P}<0.05$ vs. the control. MGO, methylglyoxal; AGEs, advanced glycation end-products; LC-MS/MS, liquid chromatography-tandem mass spectrometry; CML, $\mathrm{N}^{\varepsilon}$-(carboxymethyl)-lysine; MG-H1, $\mathrm{N}^{\delta}$-(5-hydro-5-methyl-4-imidazolone-2-yl)-ornithine; STZ, streptozotocin; Lys, lysine; Hyp, hydroxyproline.

cell viability and proliferation, and induce cytotoxicity in ST2 cells. Cell proliferation assays clearly demonstrated that $400 \mu \mathrm{M}$ MGO severely inhibited ST2 cell growth during the observation period, and lower concentrations of MGO (50 and $200 \mu \mathrm{M}$ ) could significantly, although to a much lesser extent, inhibit proliferation at day 7 of cultivation (Fig. 4A). However, no significant difference was observed among cells exposed to 0,50 , and $200 \mu \mathrm{M} \mathrm{MGO}$ at day 14 , which had already achieved confluency (Fig. 4A). Finally, ST2 cell damage was examined using an LDH assay, which monitored release of the cytoplasmic enzyme into the culture media. As expected, a significant $(\mathrm{P}<0.01)$ and dramatic increase in LDH leakage was seen with $400 \mu \mathrm{M}$ MGO (Fig. 4B), whereas $50 \mu \mathrm{M}$ MGO elicited no effect, and $200 \mu \mathrm{M}$ slightly induced cytotoxicity in cultured ST2 cells (Fig. 4B).

\section{Discussion}

In the present study, it has been demonstrated that MGO may exert a role in inhibiting osteoblastic differentiation, mineralization, and proliferation of mouse stromal ST2 cells (Figs. 3 and 4). MGO was also found to increase cell damage at higher concentrations ( $\geq 200 \mu \mathrm{M}$ ) (Fig. 4B). Concentrations of MGO in the range 50-400 $\mu \mathrm{M}$ were used in these experiments, as described previously (27). The concentration of MGO that occurs in vivo is still under debate. It has been reported that plasma MGO levels are estimated to be $\sim 0.5 \mu \mathrm{M}$ in healthy subjects, and to increase to several $\mu \mathrm{M}$ in patients with diabetes $(22,28)$. However, others reported that plasma MGO levels were in the range of $\sim 400 \mu \mathrm{M}$ in patients with poorly controlled diabetes (29). Additionally, it has been 
A

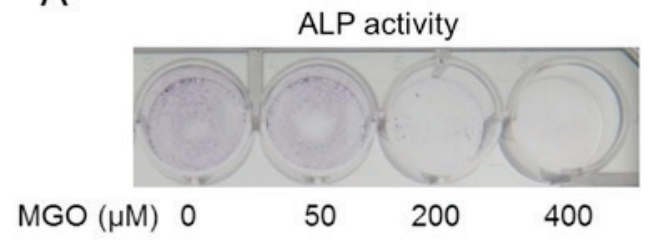

B

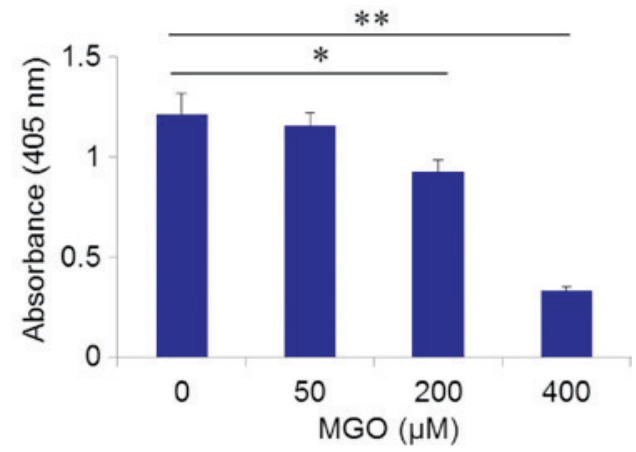

D

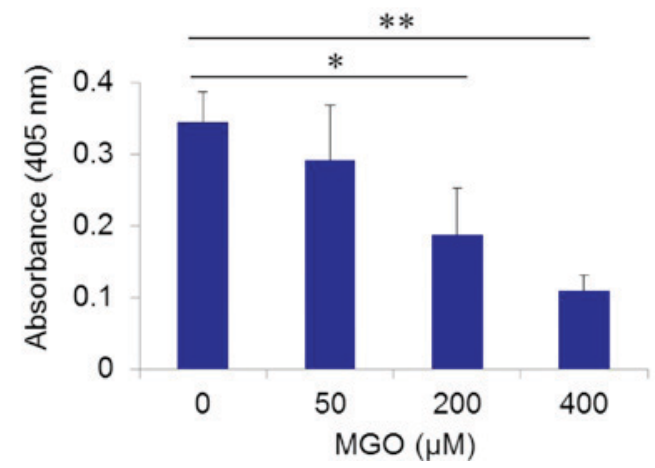

Figure 3. Osteoblastic differentiation of ST2 cells in vitro. The effect of MGO on osteoblastic differentiation was examined using mouse stromal ST2 cells. Cells were cultured in differentiation induction media containing MGO at a final concentration of $0,50,200$, or $400 \mu \mathrm{M}$. Assays for (A and B) ALP activity (measuring osteoblastic differentiation) and (C and D) alizarin red staining (measuring matrix mineralization) were performed at 7 and 28 days after ST2 cell differentiation. Values are presented as the mean \pm standard error of the mean. ${ }^{*} \mathrm{P}<0.05 ;{ }^{* * *} \mathrm{P}<0.01$ vs. control group. MGO, methylglyoxal; ALP, alkaline phosphatase.
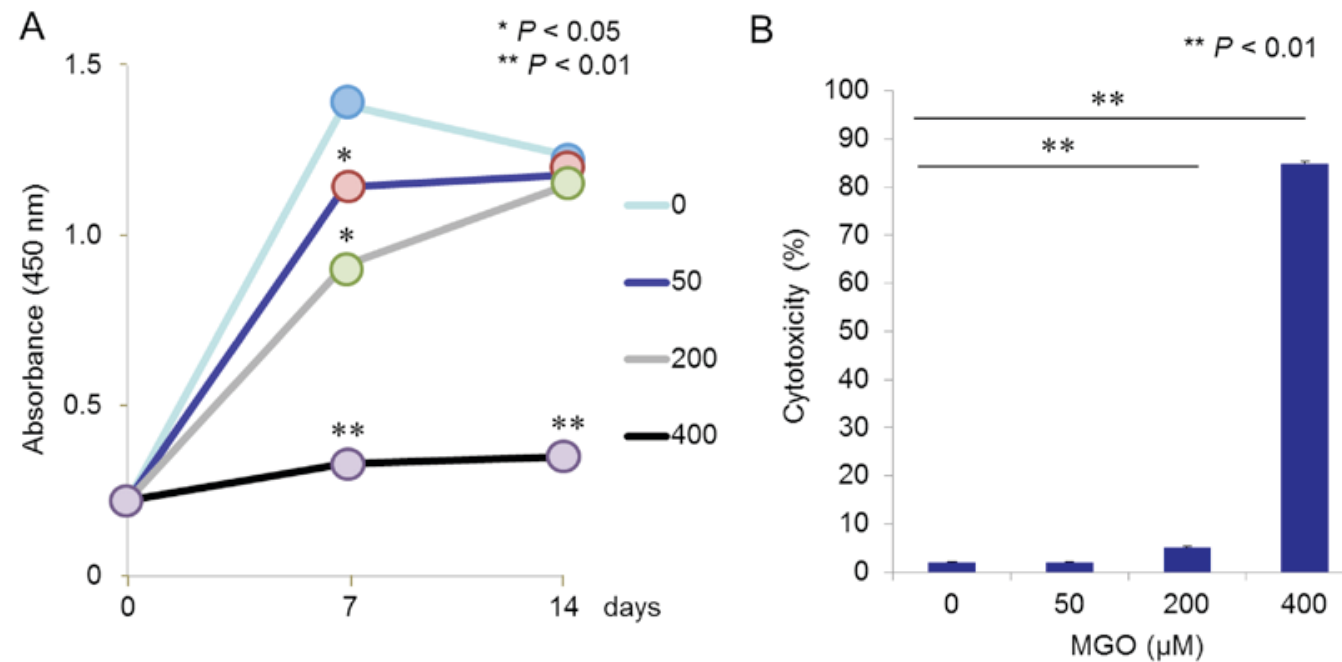

Figure 4. Cell proliferation and cytotoxicity of ST2 cells in vitro. (A) ST2 cell proliferation was assayed using the WST-1 method (40) at 7 and 14 days after induction of osteoblastic differentiation with MGO at a final concentration of $0,50,200$, or $400 \mu \mathrm{M}(\mathrm{n}=5)$. (B) Cytotoxicity was evaluated by release of the $\mathrm{LDH}$ enzyme into the culture media $(\mathrm{n}=4)$. Values are presented as the mean \pm standard error of the mean. ${ }^{* *} \mathrm{P}<0.01$ vs. control group. MGO, methylglyoxal; LDH, lactate dehydrogenase.

demonstrated that cells are able to produce large amounts of MGO (30), and therefore intracellular levels are probably much higher compared with plasma levels (31). Our hypothesis was therefore that the MGO concentrations used in the present study were neither in a non- nor a 'super'-physiological range. Chan et al (32) revealed that MGO treatment $(\sim 20 \mu \mathrm{M})$ triggered apoptotic biochemical changes in human osteoblasts.
In addition, Suh et al (27) demonstrated that MGO toxicity $(\sim 400 \mu \mathrm{M})$ in MC3T3-E1 cells, an osteoblast-like cell line, was due to oxidative stress-mediated mitochondrial dysfunction (27). This oxidative stress was also able to impair MGO detoxification processes, with a subsequent increase in endogenous MGO, which, in turn, was able to potentiate MGO-mediated protein glycation and AGE formation, with 
the further overproduction of reactive oxygen species (27). The findings of the present study, together with those of previous studies, suggest that MGO that accumulates under diabetic conditions may act on cells of the osteoblast lineage, thereby damaging their viability and functional differentiation.

In the present study, it was also demonstrated that bone repair was delayed in STZ-induced diabetic mice compared with non-diabetic control mice, using $\mathrm{CT}$ image analysis (Fig. 1). It is commonly known that fracture repair involves hematoma formation following injury, and the subsequent production of cytokines and growth factors, leading to inflammatory responses and the recruitment of mesenchymal stem cells $(33,34)$. These cells proliferate and differentiate into chondrocytes, which subsequently form new cartilage in the endochondral phase. The cells along the periosteum differentiate into osteoblasts to produce new bone. The cartilage mineralizes and mechanically stabilizes the fracture site, and the mineralized cartilage is subsequently removed by osteoclasts. The transition phase of bone formation from cartilage is involved in angiogenesis (33). Remodeling is the final step, in which osteoclasts and osteoblasts reshape the bone lesion. Previous studies have demonstrated that diabetes may impair fracture healing in almost all the above-described phases of fracture repair (2-4,6,7). In patients with diabetes, impaired recruitment of bone marrow-derived mesenchymal stem cells to the site of injury has been reported (35). Decreased and delayed bone formation was observed with the reduction of growth factor levels in diabetic animals $(36,37)$. Dysregulation of the transition from cartilage to bone has also been observed due to chondrocyte apoptosis, premature removal of cartilage, reduced osteoblast differentiation, and insufficient vascularization $(7,10-12,38,39)$. Supernormal osteoclast activity was reported to disturb remodeling of the osseous callus (7). The drill-hole injury and recovery data featured in the present study were compatible with those of previous reports, clearly indicating that diabetes may delay and damage bone healing.

In addition, representative MGO-derived AGE levels of CML and MG-H1 in the sera and femurs in STZ-induced diabetic mice, as well as in non-diabetic control mice, were measured. AGE levels were significantly increased in the sera and femurs of diabetic mice compared with those of the non-diabetic controls (Fig. 2). Notably, higher levels of MG-H1 accumulated in the femur compared with those of CML, whereas similar levels of the two AGEs were observed in sera (Fig. 2). These data suggest that the production and accumulation of MGO may be upregulated, and subsequently the concentrations of MGO-derived AGEs may build up, thereby affecting biological functions in diabetes. Okazaki et al (40) reported that AGEs, and not high glucose exposure, were able to inhibit osteoblastic differentiation and mineralization of ST2 cells by decreasing the expression of osterix, and partly by increasing the expression of receptor for AGEs (RAGE). AGEs were also shown to inhibit cell growth and increase apoptosis in ST2 cells (40). CML and MG-H1 are well-known ligands for RAGE, and their interactions may lead to diabetic complications (41). Therefore, MGO in itself, and its derivatives, such as AGE, all account for detrimental bone healing in diabetes.

Consequently, anti-glycating and quenching agents against reactive MGO may prove to be useful for the prevention and treatment of bone problems, including delayed fracture healing, in diabetes. The natural vitamin B6 analog, pyridoxamine, is a drug that may potentially be effective in diabetic nephropathy and retinopathy (42-51). Metformin is also a putative candidate (52-54). Further studies are required to investigate the effectiveness and application of anti-glycating remedies to bone problems in diabetes.

In conclusion, the present study has revealed that MGO was able to inhibit the differentiation and proliferation of osteoblasts, possibly resulting in delayed bone healing. Therefore, the detoxification of MGO, or of MGO scavengers, may improve bone repair in patients with diabetes.

\section{Acknowledgements}

We would like to thank Ms. Yoko Kasai for her assistance, and acknowledge financial support from Grants-in-Aid for Scientific Research (nos. 16K19031, 24590375, 25461335, 26450152 and 26861176) from the Japan Society for the Promotion of Science.

\section{References}

1. Vestergaard P: Discrepancies in bone mineral density and fracture risk in patients with type 1 and type 2 diabetes-a metaanalysis. Osteoporosis Int 18: 427-444, 2007.

2. Kayal RA, Alblowi J, McKenzie E, Krothapalli N, Silkman L, Gerstenfeld L, Einhorn TA and Graves DT: Diabetes causes the accelerated loss of cartilage during fracture repair which is reversed by insulin treatment. Bone 44: 357-363, 2009.

3. Retzepi M and Donos N: The effect of diabetes mellitus on osseous healing. Clin Oral Implants Res 21: 673-681, 2010.

4. Simpson CM, Calori GM and Giannoudis PV: Diabetes and fracture healing: The skeletal effects of diabetic drugs. Expert Opin Drug Saf 11: 215-220, 2012.

5. de Liefde II, van der Klift M, de Laet CE, van Daele PL, Hofman A and Pols HA: Bone mineral density and fracture risk in type-2 diabetes mellitus: The Rotterdam study. Osteoporosis Int 16: 1713-1720, 2005

6. Kayal RA, Tsatsas D, Bauer MA, Allen B, Al-Sebaei MO, Kakar S, Leone CW, Morgan EF, Gerstenfeld LC, Einhorn TA and Graves DT: Diminished bone formation during diabetic fracture healing is related to the premature resorption of cartilage associated with increased osteoclast activity. J Bone Miner Res 22: 560-568, 2007.

7. Kayal RA, Siqueira M, Alblowi J, McLean J, Krothapalli N, Faibish D, Einhorn TA, Gerstenfeld LC and Graves DT: TNF-alpha mediates diabetes-enhanced chondrocyte apoptosis during fracture healing and stimulates chondrocyte apoptosis through FOXO1. J Bone Miner Res 25: 1604-1615, 2010.

8. Loder RT: The influence of diabetes mellitus on the healing of closed fractures. Clin Orthop Relat Res: 210-216, 1988.

9. Folk JW, Starr AJ and Early JS: Early wound complications of operative treatment of calcaneus fractures: Analysis of 190 fractures. J Orthop Trauma 13: 369-372, 1999.

10. Botushanov NP and Orbetzova MM: Bone mineral density and fracture risk in patients with type 1 and type 2 diabetes mellitus. Folia Med (Plovdiv) 51: 12-17, 2009.

11. Stolzing A, Sellers D, Llewelyn O and Scutt A: Diabetes induced changes in rat mesenchymal stem cells. Cells Tissues Organs 191: 453-465, 2010

12. Sheweita SA and Khoshhal KI: Calcium metabolism and oxidative stress in bone fractures: Role of antioxidants. Curr Drug Metab 8: 519-525, 2007.

13. Sanguineti R, Storace D, Monacelli F, Federici A and Odetti P: Pentosidine effects on human osteoblasts in vitro. Ann N Y Acad Sci 1126: 166-172, 2008.

14. Alikhani M, Alikhani Z, Boyd C, MacLellan CM, Raptis M, Liu R, Pischon N, Trackman PC, Gerstenfeld L and Graves DT: Advanced glycation end products stimulate osteoblast apoptosis via the MAP kinase and cytosolic apoptotic pathways. Bone 40: 345-353, 2007. 
15. Brownlee M: Biochemistry and molecular cell biology of diabetic complications. Nature 414: 813-820, 2001.

16. Westwood ME and Thornalley PJ: Molecular characteristics of methylglyoxal-modified bovine and human serum albumins Comparison with glucose-derived advanced glycation end product-modified serum albumins. J Protein Chem 14: 359-372, 1995.

17. Phillips SA and Thornalley PJ: The formation of methylglyoxal from triose phosphates. Investigation using a specific assay for methylglyoxal. Eur J Biochem 212: 101-105, 1993.

18. Sousa Silva M, Gomes RA, Ferreira AE, Ponces Freire A and Cordeiro C: The glyoxalase pathway: The first hundred years.. and beyond. Biochem J 453: 1-15, 2013

19. Thornalley PJ: Pharmacology of methylglyoxal: Formation, modification of proteins and nucleic acids, and enzymatic detoxification-a role in pathogenesis and antiproliferative chemotherapy. Gen Pharmacol 27: 565-573, 1996.

20. Kalapos MP: Methylglyoxal in living organisms: Chemistry, biochemistry, toxicology and biological implications. Toxicol Lett 110: 145-175, 1999.

21. Vander Jagt DL and Hunsaker LA: Methylglyoxal metabolism and diabetic complications: Roles of aldose reductase, glyoxalase-I, betaine aldehyde dehydrogenase and 2-oxoaldehyde dehydrogenase. Chem Biol Interact 143-144: 341-351, 2003.

22. Scheijen JL and Schalkwijk CG: Quantification of glyoxal, methylglyoxal and 3-deoxyglucosone in blood and plasma by ultra performance liquid chromatography tandem mass spectrometry: Evaluation of blood specimen. Clin Chem Lab Med 52: 85-91, 2014.

23. Yamanaka M, Matsumura T, Ohno R, Fujiwara Y, Shinagawa M, Sugawa H, Hatano K, Shirakawa J, Kinoshita H, Ito K, et al: Non-invasive measurement of skin autofluorescence to evaluate diabetic complications. J Clin Biochem Nutr 58: 135-140, 2016.

24. Shirakawa J, Arakawa S, Tagawa T, Gotoh K, Oikawa N, Ohno R, Shinagawa M, Hatano K, Sugawa H, Ichimaru K, et al: Salacia chinensis L. extract ameliorates abnormal glucose metabolism and improves the bone strength and accumulation of AGEs in type 1 diabetic rats. Food Funct 7: 2508-2515, 2016.

25. Otsuka E, Yamaguchi A, Hirose $\mathrm{S}$ and Hagiwara $\mathrm{H}$ : Characterization of osteoblastic differentiation of stromal cell line ST2 that is induced by ascorbic acid. Am J Physiol 277: C132-C138, 1999.

26. Yamaguchi A, Ishizuya $T$, Kintou N, Wada $Y$, Katagiri $T$, Wozney JM, Rosen V and Yoshiki S: Effects of BMP-2, BMP-4 and BMP- 6 on osteoblastic differentiation of bone marrow-derived stromal cell lines, ST2 and MC3T3-G2/PA6. Biochem Biophys Res Commun 220: 366-371, 1996.

27. Suh KS, Choi EM, Rhee SY and Kim YS: Methylglyoxal induces oxidative stress and mitochondrial dysfunction in osteoblastic MC3T3-E1 cells. Free Radic Res 48: 206-217, 2014.

28. McLellan AC, Thornalley PJ, Benn J and Sonksen PH: Glyoxalase system in clinical diabetes mellitus and correlation with diabetic complications. Clin Sci (Lond) 87: 21-29, 1994

29. Lapolla A, Reitano R, Seraglia R, Sartore G, Ragazzi E and Traldi P: Evaluation of advanced glycation end products and carbonyl compounds in patients with different conditions of oxidative stress. Mol Nutr Food Res 49: 685-690, 2005.

30. Chaplen FW, Fahl WE and Cameron DC: Evidence of high levels of methylglyoxal in cultured Chinese hamster ovary cells. Proc Natl Acad Sci USA 95: 5533-5538, 1998.

31. Webb-Robertson BJ, Lowry DF, Jarman KH, Harbo SJ, Meng QR, Fuciarelli AF, Pounds JG and Lee KM: A study of spectral integration and normalization in NMR-based metabonomic analyses. J Pharm Biomed Anal 39: 830-836, 2005.

32. Chan WH, Wu HJ and Shiao NH: Apoptotic signaling in methylglyoxal-treated human osteoblasts involves oxidative stress, c-Jun N-terminal kinase, caspase-3, and p21-activated kinase 2. J Cell Biochem 100: 1056-1069, 2007.

33. Ai-Aql ZS, Alagl AS, Graves DT, Gerstenfeld LC and Einhorn TA: Molecular mechanisms controlling bone formation during fracture healing and distraction osteogenesis. J Dent Res 87: 107-118, 2008.

34. Gerstenfeld LC, Wronski TJ, Hollinger JO and Einhorn TA: Application of histomorphometric methods to the study of bone repair. J Bone Miner Res 20: 1715-1722, 2005.

35. Shin L and Peterson DA: Impaired therapeutic capacity of autologous stem cells in a model of type 2 diabetes. Stem Cells Transl Med 1: 125-135, 2012.

36. Follak N, Kloting I and Merk H: Influence of diabetic metabolic state on fracture healing in spontaneously diabetic rats. Diabetes Metab Res Rev 21: 288-296, 2005.
37. Kawaguchi H, Kurokawa T, Hanada K, Hiyama Y, Tamura M, Ogata E and Matsumoto T: Stimulation of fracture repair by recombination human basic fibroblast growth factor in normal and streptozotocin-diabetic rats. Endocrinology 135: 774-781, 1994.

38. Bahney CS, Hu DP, Miclau T III and Marcucio RS: The multifaceted role of the vasculature in endochondral fracture repair. Front Endocrinol (Lausanne) 6: 4, 2015.

39. Liao YF, Chen LL, Zeng TS, Li YM, Fan Y, Hu LJ and Ling Yue: Number of circulating endothelial progenitor cells as a marker of vascular endothelial function for type 2 diabetes. Vasc Med 15 279-285, 2010

40. Okazaki K, Yamaguchi T, Tanaka K, Notsu M, Ogawa N, Yano S and Sugimoto T: Advanced glycation end products (AGEs), but not high glucose, inhibit the osteoblastic differentiation of mouse stromal ST2 cells through the suppression of osterix expression, and inhibit cell growth and increasing cell apoptosis. Calcif Tissu Int 91: 286-296, 2012

41. Xue J, Ray R, Singer D, Böhme D, Burz DS, Rai V, Hoffmann R and Shekhtman A: The receptor for advanced glycation end products (RAGE) specifically recognizes methylglyoxal-derived AGEs. Biochemistry 53: 3327-3335, 2014.

42. Voziyan PA and Hudson BG: Pyridoxamine as a multifunctional pharmaceutical: Targeting pathogenic glycation and oxidative damage. Cell Mol Life Sci 62: 1671-1681, 2005.

43. Degenhardt TP, Alderson NL, Arrington DD, Beattie RJ, Basgen JM, Steffes MW, Thorpe SR and Baynes JW: Pyridoxamine inhibits early renal disease and dyslipidemia in the streptozotocin-diabetic rat. Kidney Int 61: 939-950, 2002

44. Zhu P, Lin H, Sun C, Lin F, Yu H, Zhuo X, Zhou C and Deng Z: Synergistic effects of telmisartan and pyridoxamine on early renal damage in spontaneously hypertensive rats. Mol Med Rep 5: 655-662, 2012

45. Waanders F, van den Berg E, Nagai R, van Veen I, Navis G and van Goor H: Renoprotective effects of the AGE-inhibitor pyridoxamine in experimental chronic allograft nephropathy in rats. Nephrol Dial Transplant 23: 518-524, 2008.

46. Alderson NL, Chachich ME, Youssef NN, Beattie RJ, Nachtigal M, Thorpe SR and Baynes JW: The AGE inhibitor pyridoxamine inhibits lipemia and development of renal and vascular disease in Zucker obese rats. Kidney Int 63: 2123-2133, 2003.

47. Tanimoto M, Gohda T, Kaneko S, Hagiwara S, Murakoshi M, Aoki T, Yamada K, Ito T, Matsumoto M, Horikoshi S and Tomino Y: Effect of pyridoxamine (K-163), an inhibitor of advanced glycation end products, on type 2 diabetic nephropathy in KK-A(y)/Ta mice. Metabolism 56: 160-167, 2007.

48. Williams ME, Bolton WK, Khalifah RG, Degenhardt TP, Schotzinger RJ and McGill JB: Effects of pyridoxamine in combined phase 2 studies of patients with type 1 and type 2 diabetes and overt nephropathy. Am J Nephrol 27: 605-614, 2007.

49. Lewis EJ, Greene T, Spitalewiz S, Blumenthal S, Berl T, Hunsicker LG, Pohl MA, Rohde RD, Raz I, Yerushalmy Y, et al: Pyridorin in type 2 diabetic nephropathy. J Am Soc Nephrol 23: 131-136, 2012.

50. Garg S, Syngle A and Vohra K: Efficacy and tolerability of advanced glycation end-products inhibitor in osteoarthritis: A randomized, double-blind, placebo-controlled study. Clin J Pain 29: 717-724, 2013.

51. Nagaraj RH, Sarkar P, Mally A, Biemel KM, Lederer MO and Padayatti PS: Effect of pyridoxamine on chemical modification of proteins by carbonyls in diabetic rats: Characterization of a major product from the reaction of pyridoxamine and methylglyoxal. Arch Biochem Biophys 402: 110-119, 2002.

52. Ruggiero-Lopez D, Lecomte M, Moinet G, Patereau G, Lagarde $\mathrm{M}$ and Wiernsperger $\mathrm{N}$ : Reaction of metformin with dicarbonyl compounds. Possible implication in the inhibition of advanced glycation end product formation. Biochem Pharmacol 58: 1765-1773, 1999.

53. Effect of intensive blood-glucose control with metformin on complications in overweight patients with type 2 diabetes (UKPDS 34). UK Prospective Diabetes Study (UKPDS) Group. Lancet 352: 854-865, 1998 .

54. Kender Z, Fleming T, Kopf S, Torzsa P, Grolmusz V, Herzig S, Schleicher E, Rácz K, Reismann P and Nawroth PP: Effect of metformin on methylglyoxal metabolism in patients with type 2 diabetes. Exp Clin Endocrinol Diabetes 122: 316-319, 2014 